\title{
Depression after Delivery: Risk Factors, Diagnostic and Therapeutic Considerations
}

\author{
Debra A. Scrandis ${ }^{1,2, *}$, Tehmina M. Sheikh ${ }^{1,3}$, Robina Niazi ${ }^{1,3}$, \\ Leonardo $\mathrm{H}$. Tonelli ${ }^{1}$, and Teodor T. Postolache ${ }^{1}$ \\ ${ }^{1}$ Mood and Anxiety Program, Department of Psychiatry, University of Maryland \\ School of Medicine, MSTF Building, Room 502, 685 West Baltimore Street, \\ Baltimore, MD 21201; ' School of Nursing, University of Maryland, 655 West \\ Lombard Street, Room 675D, Baltimore MD 21201; ${ }^{3}$ Residency Training Program, \\ St. Elizabeth's Hospital, 2700 Martin Luther King Avenue, Washington, D.C. 20032 \\ E-mail: dscrandi@psych.umaryland.edu
}

Received June 17, 2007; Revised July 12, 2007; Accepted July 13, 2007; Published October 22, 2007

Postpartum mood disorders can negatively affect women, their offspring, and their families when left untreated. The identification and treatment of postpartum depression remains problematic since health care providers may often not differentiate postpartum blues from depression onset. Recent studies found potentially new risk factors, etiologies, and treatments; thus, possibly improving the untreated postpartum depression rates. This integrated review examined several postpartum psychiatric disorders, postpartum blues, generalized anxiety, obsessive compulsive disorder, posttraumatic stress disorder, and postpartum psychosis for current findings on prevalence, etiologies, risk factors, and postpartum depression treatments.

KEYWORDS: postpartum depression, postnatal depression, postpartum mood disorders, postpartum blues, depression treatments, women

\section{INTRODUCTION}

Postpartum depression (PPD) is a major public health problem that requires early detection, early intervention, educational efforts to increase awareness, and research efforts to better understand its mechanisms and to find better interventions[1]. Despite the evidence of poor outcomes from chronic depression in women after childbirth, diagnosis and treatment rates for PPD have not shown significant long-term improvement[2]. There are multiple etiologies suggested for these poor detection and management rates. Women may be reluctant to admit to having a mood disorder due to the stigma of mental illness or they may attribute their symptoms, such as mood changes, sleep disturbances, fatigue, and sexual impairment, to the normal postpartum period[3]. Routine screening in primary care provider offices is not being conducted consistently[4], and if it is done, it encounters difficulties of differentiating between PPD and the postpartum blues, which results in inadequate prognostic considerations and treatment options. Once PPD is identified, various therapies are available for treating this disorder. This integrative review examined recent prevalence, etiologies, and risk factors of postpartum psychiatric disorders, as well as diagnostic and treatment options specifically for PPD. 


\section{Postpartum Mood Disorders}

Over the years, there has been significant discussion on whether postpartum mood disorders are distinct diagnoses, part of a continuum from mild to severe distress, or the same as major PPD depression at any other point in life[5,6,7,8,9]. More recently, these mood changes, postpartum blues, and PPD depression are thought to be unique disorders with significant symptom differences and comorbidity $[10,11]$.

\section{Postpartum Blues}

Postpartum blues, also known as the baby or maternity blues, is a condition affecting between $20-85 \%$ of women after delivery[12,13,14,15]. This wide prevalence range results from the use of different instruments to assess tearfulness or sadness, not the complete syndrome of the blues[16]. The postpartum blues is a transient disorder. Symptoms of intermittent tearfulness, despondency, anxiety, and poor concentration usually begin between 3-4 days postpartum and last between 1-7 days[14]. The anxiety symptoms usually relate to situational difficulties, such as breastfeeding problems. Symptoms usually remit within 2 weeks postpartum.

The postpartum blues may be an inappropriate term to describe these symptoms: rather, this time period may be postpartum reactivity, including a heightened labiality of mood in reaction to stimuli resulting possibly from hormonal withdrawal[17].

The neurochemical etiologies of the blues are not conclusive; only two small studies found an association between low serum progesterone (including alloprenanolone) levels at day 2-3 and the maternity blues[18,19]. One animal study found that high levels of $17 \beta$-estradiol suppressed $5 \alpha$-reductase expression and progesterone in the brain, contributing to postpartum mood disorders, particularly the blues[20]. Three recent studies attributed increased degradation of tryptophan to kynurenine (often occurring after immune activation) in the onset of postpartum blues[21,22,23].

The symptoms of the postpartum blues are distinctly different from PPD. During the first 2 weeks postpartum, if women have depressed moods that increase in severity rather than decrease, they may be experiencing PPD. In some high-risk women, the postpartum blues may predict the development of $\mathrm{PPD}[24]$.

\section{Postpartum Depression}

PPD is a complex mix of physical, emotional, and behavioral changes that occur after giving birth that are attributed to the genetic, social, and psychological changes associated with having a baby[25]. The Diagnostic and Statistical Manual of Mental Disorders $4{ }^{\text {th }}$ Edition: Text Revised (DSM-IV TR)[26] views PPD as Major Depression with a Postpartum Onset occurring approximately within 4 weeks after delivery. Symptoms include anhedonia, dysphoria, hopelessness, worthlessness, anxiety, inability to sleep while infant is asleep, poor concentration, appetite disturbances, guilt, and suicidal thoughts. Untreated PPD can lead to chronic depression, maternal infant interaction disturbances, suicide, and in rare cases, infanticide[27]. It is important to note that up to $20 \%$ of postpartum deaths are attributed to suicide due to $\mathrm{PPD}[28]$.

The period prevalence of major PPD is estimated to be 5.7\%; however, studies have not found any conclusive evidence for incidence rates[29]. Findings suggested similar epidemiological rates among Latina, African American, and Caucasian women[30,31]. Two separate studies reported PPD prevalence in Native American women[32] and Immigrant Asian Indian women[33]. However, this prevalence rate was based on self-reported PPD symptoms without a specific diagnosis of PPD. Again, limited prevalence data exist on Asian and Pacific postpartum women in the U.K. and New Zealand since rates were self-reported[34,35].

A recent epidemiological study[36] in Denmark examined a register-based cohort of over 2.3 million Danish-born persons to determine the relative risk of becoming a first-time parent (mothers and fathers), 
and hospital admission or outpatient contact for a mental disorders within 1 year postpartum. Mothers were at highest risk of being admitted for unipolar depressive disorders at 31-60 days postpartum (RR $3.53,95 \%$ CI 2.47-5.05). Primiparous women were at greater risk than multiparous women. Fathers were not significantly at risk for hospital admission or outpatient contact for a mental disorder. This population-based study provided evidence of first-time childbearing and PPD as a significant public health problem that needs quick identification and subsequent rapid treatment[1].

Postpartum anxiety disorders, such as obsessive compulsive disorder (OCD), panic disorder, and post-traumatic stress disorder (PTSD), are common disorders that occur alone or in combination with major PPD. While in certain cases these disorders are closely associated with pregnancy or delivery, in many other cases, it appears that pregnancy and the perinatal period exacerbate previously latent or minimally symptomatic anxiety disorders. The key feature of these disorders is extreme anxiety. In OCD, women have intrusive, repetitive thoughts that may center on harming the infant and they are horrified to have these thoughts. Sometimes, women have certain behaviors that alleviate the anxiety, such as counting or frequently checking locks. Panic disorder is episodic extreme anxiety with physical symptoms, such as shortness of breath and heart palpitations. PTSD has symptoms of recurrent nightmares and reliving past traumatic events, such as sexual abuse[37]. There is limited research on the prevalence of anxiety disorders; however, the rates of OCD and generalized anxiety disorder are higher in the postpartum period than in the general population[38]. One study reported the incidence of PTSD in about $2 \%$ of deliveries[39]. One community sample $(n=156)$ found that $19.8 \%$ had at least one anxiety disorder (specifically panic disorder and/or OCD) and depression at 4-7 months postpartum[40], further supporting the comorbidity of these disorders. No studies examining the etiologies for postpartum anxiety disorders were found, and longitudinal studies would be important to identify risk factors and treatments.

\section{Risk Factors of Postpartum Depression}

The strongest predictors of developing PPD include depression and/or anxiety during pregnancy, stressful life events during pregnancy and/or postpartum, low levels of social supports, and personal history of depression prior to pregnancy[24,41]. Studies on family history of depression, anxiety, or PPD show mixed results[42,43,44]. Other risk factors include women with premenstrual dysphoric disorder[45]; adolescents, lower income[46] and recent eating disorders[47]. One study $(n=16)$ provided some support for estrogen/progesterone and PPD onset in women with a previous history of the disorder. These women may be specifically sensitive to the effects of gonadal steroids, thereby contributing to depressive $\operatorname{mood}[48]$.

\section{Diagnostic Challenges of Postpartum Depression}

Early detection through screening and early management of PPD are critical in order to decrease poor outcomes for women and their families[49]. Prenatal depression is a high risk factor for the development of PPD, and it is debatable whether PPD may be a continuation of prenatal depression[50]. However, treating prenatal depression was not highly endorsed due to the possible negative effects of medications on the fetus. For instance, case reports suggested that serotonin-selective receptor inhibitors during the third trimester led to newborn withdrawal syndrome[51]. On the other hand, in the past 5-7 years, research on the devastating effects of untreated prenatal depression, such as poor self-care and prenatal care attendance, added to the controversy of antidepressant therapy during pregnancy[52]. Despite these reports, treatment for prenatal depression was reported in only $33 \%$ of women diagnosed with depression and who had a previous history of depression $(n=276)[53]$. Therefore, the benefits and risks of psychotropic medications need to be considered, depending on the patients' symptoms and clinical judgment of the clinician[54].

Symptoms of major depression tend to overlap with what is considered to be normal changes in the postpartum period. For example, isolated occasional crying, weight changes, sleep disturbances, and 
fatigue are not uncommon among new mothers. Women lose weight after pregnancy and tend to consider sleep disturbances normal for the postpartum period. Frustration manifested by crying and fatigue further complicates the accurate assessment of PPD. Since women do not self-recognize their symptoms as abnormal, they are not likely to discuss them with health care providers. If screening does occur and women at high risk for PPD are referred to psychiatric care by their health care providers, women may not still attend appointments, often due to the stigma, sometimes due to lack of time and availability of convenient providers, and often because of symptoms themselves (lack of energy, motivation, and hopelessness). Minorities, such as African Americans, Hispanics, and other ethnic groups, are particularly at risk[55]. Language used by clinicians is important to consider in minimizing stigma. PPD may not be an acceptable term for mothers, especially for women from other cultures. A key challenge in diagnosis is the women's ability to self-recognize that they feel different and need treatment for PPD. Women may tend to normalize their symptoms and thus not discuss their symptoms with health care providers[56]. See Table 1 for a summary of symptoms, onset, impairment level, length of disorder, and diagnoses to rule out when assessing women for possible postpartum psychiatric disorders.

\section{Screening}

The primary goal of the assessment process is to identify women at risk for PPD as well as women already in the depths of depression, and to evaluate women at immediate risk for self and others (e.g., suicidality, postpartum psychosis). Screening for PPD identifies more cases than relying on provider identification alone in a variety of patient populations and countries[57]. While the U.K. and Australia embraced routine screening, assessment for PPD has not become standard in the U.S. On a positive note, New Jersey enacted legislation that all licensed health care providers who provide perinatal care to screen for provide education and if needed resources for PPD[58]. Screening does not take the place of a complete psychiatric evaluation. However, early identification during pregnancy and the postpartum period would aid in referring women for further evaluation[50].

Self-report instruments that could be useful when screening for PPD include the Edinburgh Postnatal Depression Scale (EPDS)[59] and the Postpartum Depression Screening Scale (PDSS)[60]. The EPDS is a 10-question self-report instrument that rates symptoms on a scale of 0 to 3 . A total score over 12 or 13 has been correlated with major depression with adequate sensitivity and specificity. This instrument has also been validated in numerous languages for assessing women from multiple cultures. The PDSS is a 35-item self-report instrument assessing seven symptoms on a scale of 1 (strongly disagree) to 5 (strongly agree). These symptoms include guilt/shame, mood changes, lack of concentration, anxiety, sleep/eating disturbances, loss of self, and suicidal ideation. Both instruments have excellent psychometrics, though the PDSS was found to have a higher sensitivity and specificity for major depression[61].

\section{Postpartum Psychosis}

Postpartum psychosis is a severe, but rare, psychiatric disorder that may or may not coexist with PPD. In fact, only 1-4 in 1,000 women without prepregnancy or prenatal psychotic or bipolar episodes will experience postpartum psychosis, while about $4.5-9.3 \%$ of women may have postpartum psychosis if they had prepregnancy or prenatal psychotic disorders or bipolar episodes[62]. Women who have bipolar I disorder and family histories of postpartum psychosis are six times more likely to experience postpartum psychosis than women with bipolar I disorder alone[63]. Women diagnosed with postpartum psychosis are likely to experience further episodes of psychosis during their lifetime[64]. A large Swedish study found 
TABLE 1

Postpartum Psychiatric Disorders

\begin{tabular}{|c|c|c|c|c|}
\hline & Baby Blues & Minor Depression & Major PPD & $\begin{array}{l}\text { Postpartum } \\
\text { Psychosis }\end{array}$ \\
\hline Symptoms & $\begin{array}{l}\text { Anxiety }{ }^{2} \text { about infant } \\
\text { and parenting, } \\
\text { teary, } \\
\text { overwhelmed, } \\
\text { fluctuation of } \\
\text { positive and } \\
\text { negative moods }\end{array}$ & $\begin{array}{l}\text { Similar symptoms of } \\
\text { major depression, but } \\
\text { with less symptoms } \\
\text { and less impairment }{ }^{3}\end{array}$ & $\begin{array}{l}\text { Low mood, severe } \\
\text { anxiety }^{1-3} \text {, feeling } \\
\text { overwhelmed, } \\
\text { possible panic } \\
\text { attacks, } \\
\text { hopelessness, }^{2} \\
\text { suicidal thoughts }^{2}\end{array}$ & $\begin{array}{l}\text { Anxiety-vague, labile, } \\
\text { low or elevated mood, } \\
\text { preoccupied, } \\
\text { distracted delusions } \\
\text { and hallucinations }\end{array}$ \\
\hline Onset & $\begin{array}{l}\text { Within } 10 \text { days } \\
\text { postpartum }^{3}\end{array}$ & $\begin{array}{l}\text { May start early } \\
\text { postpartum }\end{array}$ & $\begin{array}{l}\text { Within } 4 \text { weeks } \\
\text { postpartum }^{3}\end{array}$ & $\begin{array}{l}\text { Acute onset, rapid, first } \\
\text { few days to } 2-3 \\
\text { weeks postpartum }^{2}\end{array}$ \\
\hline $\begin{array}{l}\text { Level of } \\
\text { impairment }\end{array}$ & $\begin{array}{l}\text { Fluctuates, some } \\
\text { good days, mood } \\
\text { not necessarily } \\
\text { low all day }\end{array}$ & $\begin{array}{l}\text { Will be able to function, } \\
\text { but with more effort }\end{array}$ & $\begin{array}{l}\text { Feeling low most of } \\
\text { the time for most } \\
\text { days }\end{array}$ & $\begin{array}{l}\text { Can deteriorate rapidly, } \\
\text { psychiatric emergency }\end{array}$ \\
\hline Time course & $\begin{array}{l}\text { Usually improves } \\
\text { over first few } \\
\text { months }\end{array}$ & $\begin{array}{l}\text { Lasts at least } 2 \text { weeks, } \\
\text { all day }\end{array}$ & $\begin{array}{l}\text { Incidence rises within } \\
30 \text { days }^{4} \text {, can last } \\
\text { months, years }\end{array}$ & Varies \\
\hline Assessment & $\begin{array}{l}\text { Follow to assess for } \\
\text { minor depression/ } \\
\text { major depression } \\
\text { lasting more than } \\
2 \text { weeks }\end{array}$ & $\begin{array}{l}\text { Follow to assess } \\
\text { worsening of } \\
\text { symptoms to MDD, } \\
\text { risk for suicide }\end{array}$ & $\begin{array}{l}\text { Risk of suicide, } \\
\text { neglect of infant } \\
\text { and/or poor } \\
\text { parenting, } \\
\text { psychotic } \\
\text { symptoms }\end{array}$ & $\begin{array}{l}\text { May be harmful to self } \\
\text { and/or infant due to } \\
\text { poor judgment, } \\
\text { command } \\
\text { hallucination or } \\
\text { delusional beliefs, } \\
\text { needs hospitalization }\end{array}$ \\
\hline
\end{tabular}

1 Chabrol, H. and Teissedre, F. (2004) Relation between Edinburgh Postnatal Depression Scale scores at 2-3 days and 4-6 weeks postpartum. J. Reprod. Infant Psychol. 22, 33-39.

2 Buist, A. (2006) Perinatal depression-assessment and management. Aust. Fam. Physician 35(9), 670-673.

3 American Psychiatric Association (2000) Diagnostic and Statistical Manual of Mental Disorders $4^{\text {th }}$ Edition: Text Revised. American Psychiatric Association, Washington, D.C.

4 Cooper, P.J. and Murray, L. (1995) Course and recurrence of postnatal depression: evidence for the specificity of the diagnostic concept. Br. J. Psychiatry 166, 191-195.

that women from poorer neighborhoods were $43 \%$ more likely to be admitted for postpartum psychosis than women from more affluent neighborhoods[65]. However, it is unclear how socioeconomic status influences onset of psychosis unless high-risk women are unable to continue employment. Family history of psychosis as well as bipolar I disorder appears to be a significant risk factor. The onset of postpartum psychosis tends to be rapid, occurring within the first 3-5 days after delivery and may last 1 week to several months without treatment. Symptoms include severe agitation, confusion, feeling of hopelessness and shame, insomnia, paranoia, delusions or hallucinations, hyperactivity, rapid speech, or mania. These delusions frequently focus on denying the baby's existence or the need to kill herself and/or the infant. This disorder requires immediate medical attention usually resulting in separation of the mother from the child, and psychiatric hospital admission. One pilot study found that the administration of $17 \beta$-estradiol diminished psychotic symptoms within 2 weeks in women with postpartum psychosis and estrogen deficiencies[66], suggesting a possible etiology of postpartum estrogen withdrawal in vulnerable women. There is limited research on postpartum psychosis treatments, especially preventative treatment in highrisk women. 


\section{TREATMENT OPTIONS}

\section{Nonpharmacological Treatments}

Research has shown several types of psychotherapy to be effective for PPD: interpersonal psychotherapy (IPT), cognitive behavioral therapy (CBT), and group/family therapy. Two small randomized controlled trials (RCTs) found symptom reductions in women diagnosed with PPD through nurse-delivered CBT[67], maternal infant dyad group therapy (M-IGT), and individual IPT[68] after 8 weeks of treatment. No data analyses identified either M-IGT or IPT to be superior for treatment of depression. One larger RCT $(n=120)$ found IPT effective in decreasing PPD symptoms as opposed to waiting-list condition[69]; however, when various methods of psychotherapy and control are compared in one RCT $(\mathrm{n}=193)$, depressive symptoms reduce at 4.5 months, but without any significant difference between treatments (CBT, psychodynamic therapy, and nondirective counseling) Further, there were no lasting effects of depression reduction at 9, 18, or 60 months postpartum[70]. One study tested adaptation of IPT to group settings without a control group, with significant reduction of depressive symptoms[71]. These study samples failed to include various minorities (only Caucasian women); thus, the effectiveness is unknown for other groups. Psychotherapies may be helpful for breastfeeding mothers who are reluctant to use or continue antidepressants[72,73,74,75]. However, the time commitment of therapy may pose a burden for new mothers. One study found that high-risk women who preferred counseling treatment (controlling for antenatal depression and demographics) were six to eight times more at risk to have depressive symptoms at 3 and/or 6 months postpartum than women who did not prefer counseling[76].

\section{Antidepressant Treatment}

One case-control study found that women diagnosed with PPD presented with significantly more anxiety symptoms, had less treatment response to antidepressant medication, and were more likely to be experiencing marked or severe depression than nonpostpartum women with depression[77]. Therefore, treatment with antidepressant therapy needs to be tailored specifically for PPD. Furthermore, three case studies reported the onset of mania after antidepressant therapy with postpartum women[78]. Thus, caution is recommended upon the initiation of antidepressant treatment in women[79]. Table 2 summarizes antidepressant treatment studies to date.

One double-blinded RCT $(n=109)$ compared the effectiveness of sertaline and nortriptyline for remission of PPD after 8 weeks of treatment in a mixed racial sample. There was no significant difference between the two therapies; however, women who responded to sertaline or nortriptyline had $50 \%$ reduction in depressive symptoms by 2 and 4 weeks, respectively. The side effect profile reported for sertaline was lower than nortriptyline. Furthermore, breast milk levels of both sertaline and nortriptyline were undetectable in breastfeeding women[80].

One early RCT $(n=87)$ [81] compared fluoxetine alone, fluoxetine in combination with one or six sessions of psychotherapy, and counseling only. No significant difference in effectiveness was found for any of the treatments, and all groups had decreased depressive symptoms. No breastfeeding women were included in the sample. More recently, fluoxetine was shown to have a wide range of drug levels in breast milk during 6 weeks of treatment for ten mother-infant dyads[82].

One single-blind study found that $60 \%$ of women responded to fluvoxamine titrated over 8 weeks. However, the small sample size and lack of breast milk data limits these findings[83]. 
TABLE 2

Summary of Antidepressant Therapy for PPD

\begin{tabular}{|c|c|c|c|c|c|c|}
\hline Sample $(n)$ & Design & Measure & Treatment & $\begin{array}{c}\text { Length of } \\
\text { Trial }\end{array}$ & Comments & Ref. \\
\hline 8 & $\begin{array}{l}\text { Pre- } \\
\text { experimental }\end{array}$ & HSD & Bupropion SR & 8 weeks & $\begin{array}{l}80 \% \text { sample } \\
\text { decrease of } \\
50 \% \\
\text { symptoms, } \\
20 \% \text { remission }\end{array}$ & [84] \\
\hline 15 & $\begin{array}{l}\text { Pre- } \\
\text { experimental }\end{array}$ & $\begin{array}{l}\text { HSD, Kellner } \\
\text { symptom } \\
\text { questionnaire }\end{array}$ & $\begin{array}{l}\text { Venalfaxine } \\
\text { immediate } \\
\text { release, flexible } \\
\text { dose }\end{array}$ & 8 weeks & $80 \%$ remission & [85] \\
\hline 109 & $\begin{array}{l}\text { Double-blind } \\
\text { randomized } \\
\text { comparative }\end{array}$ & HSD & SERT, NTP & 8 weeks & $\begin{array}{l}46-48 \% \text { sample } \\
\text { with } 50 \% \\
\text { reduction } \\
\text { symptoms in } \\
\text { both groups }\end{array}$ & [80] \\
\hline 6 & $\begin{array}{l}\text { Open label } \\
\text { trial }\end{array}$ & HSD & $\begin{array}{l}\text { FLOUXM titrated } 50 \\
\text { mg to } 150 \\
\text { mg/day, } M=142 \\
\text { mg }(\mathrm{SD}=20)\end{array}$ & 8 weeks & $\begin{array}{l}66 \% \text { responded } \\
\text { with decreased } \\
\text { symptoms on } \\
\text { HAMD (over } 17 \\
\text { to 2), no breast } \\
\text { milk collected }\end{array}$ & [83] \\
\hline 87 & $\begin{array}{l}\text { RCT double } \\
\text { blind }\end{array}$ & EPDS, HSD & $\begin{array}{l}\text { FLOUXT and } \\
\text { placebo with } 1 \text { or } \\
6 \text { counseling } \\
\text { sessions }\end{array}$ & 12 weeks & $\begin{array}{l}\text { Excluded } \\
\text { breastfeeding } \\
\text { women, no } \\
\text { significant } \\
\text { difference }\end{array}$ & [81] \\
\hline
\end{tabular}

HSD: Hamilton Depression Rating Scale; EPDS: Edinburgh Postnatal Depression Scale; SERT: sertaline; NTP: nortriptyline; FLUOXT: fluoxetine; FLUOXM: fluoxamine.

\section{Alternative Therapies}

Research studies are examining other options for PPD treatment. For example, omega 3 fatty acid has nutritional value to pregnant women and their infant, and lower serum levels of polyunsaturated fatty acids (PUFA) have been shown to be predictive of PPD[86]. Other studies found similar results; low DHA increased the risk of PPD in a large sample $(n=112)[87]$ and high DHA in mother's milk and seafood consumption predicted decreased PPD prevalence[88]. In an animal model, temporal lobes and frontal cortex were most affected by a DHA-depleted diet[89]. Studies on DHA supplementation for PPD found mixed results. One small randomized trial $(n=16)$ found about $50 \%$ decrease in PPD symptoms after 8 weeks of eicosapentaenoic acid (EPA) and docosahexaenoic acid (DHA) $0.5 \mathrm{mg} / \mathrm{day}, 1.4 \mathrm{~g} / \mathrm{day}$, or $2.8 \mathrm{~g} /$ day. No significant difference was found between any of the doses for depressive symptoms[90]. Other studies examined the risk of PPD, fish intake, fish/olive oil, and DHA; however, they did not have any positive results[91,92,93]. Many of the participants were not diagnosed with PPD and relied on selfreport. Side effects were not found, but more longitudinal studies with placebo groups would assist in differentiating the effectiveness of this modality for PPD.

Studies examined Hypericum perforatum (St. John's wort) for major depression. Recent evidence review of RCTs found no significant difference between $H$. perforatum and placebo for major depression[94]. One randomized placebo-controlled study examined neurobehavioral changes in developing mice exposed to Hypericum $(0.75 \mathrm{mg} / \mathrm{g}$ of food consumed daily, comparable to dosages in humans) vs. placebo at 2 weeks before conception and during pregnancy. Findings found no significant 
difference between the treatment and placebo group in motor coordination, vocalization, cognition, motivation, depressive and anxiety-like behaviors, and social play[95]. Another case study examined histological changes in rats after exposure of Hypericum (100 vs. $1000 \mathrm{mg} / \mathrm{kg} / \mathrm{day}$, comparable to human dosages) 2 weeks before conception, antenatal, and breastfeeding. This study found significant liver and renal damage with both dosages. The severity of the damage was related to the increased dosage strength[96]. No RCT studies examined the effects of Hypericum in pregnancy, breastfeeding, or PPD in humans. Two small longitudinal studies found limited infant adverse events during Hypericum exposure and breastfeeding[97,98]. The available data do not support the use of Hypericum in postpartum treatment, and caution should be exercised.

Bright light treatment produced antidepressant effects in an open trial $(n=16)$ of antenatal depressed women[99]. One letter reviewed two case reports that demonstrated $75 \%$ reduction in symptoms from light treatment[100]. A recent RCT $(n=10)$ showed women with antenatal depression and 10 weeks of 7000 lux light box had significant improvement (effect size $0.43, p=0.001$ ) compared with women who received 500 lux or 5 weeks of 7000 lux[101]. Treatment risks are limited. No postpartum studies of light treatment have been conducted, to our knowledge.

\section{Electroconvlusive Therapy}

Electroconvulsive therapy has been effective in major depression disorder and may also be effective with PPD. However, no studies to date systematically examined this treatment option with postpartum women. Even without studies, clinically, ECT should be considered in severe, suicidal PPD and in postpartum psychosis.

\section{Hormonal Treatment}

Estrogen and progesterone decrease drastically after placental delivery, and a possible "endogenous gonadal-steroid withdrawal" has been hypothesized to contribute to mood changes. Ahokas et al.[102] found sublingual $17 \beta$-estradiol effective in reducing severe postpartum depressive symptoms by half within the first week in women with low baseline serum estradiol concentrations. This study included breastfeeding women, with no reports of diminished milk supply or infant feeding difficulties. No adverse events from estrogen treatment (e.g., endometrial hyperplasia, thromboembolism) were reported. One double-blind placebo-controlled study $(n=61)$ of women who were diagnosed with PPD randomized to $200 \mathrm{mg}$ 17ß-estradiol transdermal patches for 6 months or no treatment[103]. This study found significant differences between the treatment and placebo group. Fifty percent of the treatment group rated themselves lower than the study's identified threshold of 14 on the EPDS at 1 month and $80 \%$ of the women reported below the EPDS threshold at 3 months. The placebo group did improve in the depressive symptoms; however, their scores on average were not below the EPDS threshold for at least 4 months. Although these data suggest a more rapid improvement with estrogens, additional larger studies are necessary, with different dosages, and with consideration for safety, before estrogen may be considered an established treatment for PPD[104].

Progesterone enhances GABA in the central nervous system, producing anxiolytic and hypnotic effects; therefore, it may play a role in treating PPD with comorbid anxiety. Although one double-blinded RCT $(n=100)$ found that depot norethisterone enanthate given within 48 hours after delivery increased the risk of developing PPD at 6 weeks postpartum and significantly suppressed endogenous $17 \beta$-estradiol vs. placebo $(p<0.0001)[105]$. Caution is recommended in using progestin in women at high risk for $\operatorname{PPD}[105]$.

\section{Treatment Summary}


In summary, many women with PPD remain untreated, possibly from lack of information about treatment effectiveness and residual effects of antidepressants in nursing infants[79]. Serotonin-selective reuptake inhibitors (SSRIs) are considered the drug class of choice. However, all antidepressants cross into breast milk and milk-to-plasma ratios do not accurately predict safety to milk supplies. According to pooled data, SSRIs, and specifically sertraline and paroxetine, offer the best safety profile[106]. The benefits of taking antidepressants will have to be individually weighted against the risks of infant exposure to psychotropics. Benefits will probably outweigh the risks when moderate to severe symptoms, with significant functional deterioration or progressive worsening, are in place. Obviously artificial feeding alleviates concerns of infant psychotropic exposure.

The treatment of postpartum psychosis is beyond the scope of this article, but it is based on combinations of antidepressants, antipsychotics and, considering the association with bipolar disorder, sometimes, mood stabilizers. ECT is another safe and effective alternative. Emergency psychiatric hospitalization of the mother is one of the most difficult decisions the psychiatrist must make in postpartum psychiatric disorders.

\section{Emergency Psychiatric Hospitalization}

No formal diagnostic criteria and guidelines for postpartum psychiatric disorders exist to assist psychiatrists with these critical diagnostic and treatment decisions[107]. Most of the literature discussed postpartum psychosis as needing immediate hospitalization and separation of the mother from the child[108]. Collateral information is absolutely necessary, and evaluation of the degree of family support available for mothers is essential for the adequate risk/benefit analysis of separating the mother from the infant and hospitalization. When women have severe PPD symptoms (e.g., lack of interest in the infant, excessive concern for infant's health, impaired functioning, suicidal or homicidal ideation, and especially intent or plan), the safety of emergency hospitalization outweighs the concerns of separating the mother and infant, familial difficulties, and stigma[109].

\section{Immunological Considerations}

Studies are under way to identify unconsidered vulnerabilities and triggers for PPD that may provide new prognostic factors and identify novel therapeutic targets for PPD. Among them, the role that the immune system may play in the etiology of PPD is under consideration, in the context that imbalances in the immune system are associated with mood disorders in general[110,111]. The relationship between depression and the immune system might be particularly relevant for PPD, considering the postpartum rebound from the relative immunosuppression necessary for the mother to immunologically tolerate the embryo and the fetus, the physical trauma of birth, the exposure at birth of open wounds to bacteria from the urinary and gastrointestinal tract, and the effects of estrogen-progesterone deprivation postpartum on the immune system.

\section{CONCLUSIONS}

Research studies continue to examine the etiologies and spectrum of postpartum psychiatric disorders. Distinguishing postpartum mood disorders, improving identification of PPD, and treating with effective therapies can decrease the poor outcomes associated with chronic and severe depression in postpartum women. This literature review identified mixed findings among various treatment options available. Antidepressant treatment is relatively safe and effective. Psychotherapy offers some hope, and may be a good indication as a combined treatment or as monotherapy in milder cases in women who breastfeed and are opposed to medications. Randomized control studies are badly needed for all PPD treatments. At times, the benefits of hospitalization, including involuntary hospitalization, when psychotic, suicidal, 
infanticidal, or failure to sustain daily needs of mother or child considerations are present, outweigh concerns related to separating the mother and child; developmental implications in the infant; and stigma, guilt, and shame in the mother. Additional research is necessary to uncover better prognostic factors as well as new treatments for PPD and related conditions.

\section{REFERENCES}

1. Wisner, K., Chambers, C., and Sit, D. (2006) Postpartum depression: a major public health problem. JAMA 296, 2616-2618.

2. Agency for Health Care Research and Quality (2006) Half of postpartum depression cases are not recognized. Research Activities Newsletter. No. 310. AHRQ Publication No. 06-0052. Agency for Healthcare Research and Quality, Rockville, MD.

3. Coates, A., Schaefer, C., and Alexander, J. (2004) Detection of postpartum depression and anxiety in a large health plan. J. Behav. Health Serv. Res. 31, 117-133.

4. Seehusen, D., Baldwin, L., Runkle, G., and Clark, G. (2005) Are family physicians appropriately screening for postpartum depression? J. Am. Board Fam. Pract. 18, 104-112.

5. Whiffen, V.E. (1992) Is postpartum depression a distinct diagnosis? Clin. Psychol. Rev. 12, 485-508.

6. Steiner, M. and Tam, W. (1999) Postpartum depression in relation to other psychiatric disorders. In Postpartum Mood Disorders. Miller, L., Ed. American Psychiatric Press, Washington, D.C. pp. 47-63.

7. Campbell, S. and Cohn, J. (1991) Prevalence and correlates of postpartum depression in first-time mothers. J. Abnorm. Psychol. 100, 594-599.

8. Cooper, P.J. and Murray, L. (1995) Course and recurrence of postnatal depression: evidence for the specificity of the diagnostic concept. Br. J. Psychiatry 166, 191-195.

9. Whiffen, V. and Gotlib, I. (1993) Comparison of postpartum and nonpostpartum depression: clinical presentation, psychiatric history, and psychosocial functioning. J. Consult. Clin. Psychol. 61, 485-494.

10. Chaudron, L. (2005) Postpartum depression in pediatric practices: opportunities and challenges. In Women and Depression. National Institute of Health, Bethesda, MD.

11. Wisner, K., Peindl, K., Gigliotti, T., and Hanusa, B. (1999) Obsessions and compulsions in women with postpartum depression. J. Clin. Psychiatry 60, 176-180.

12. Josefsson, A., Berg, G., Nordin, C., and Sydsjo, G. (2001) Prevalence of depressive symptoms in late pregnancy and postpartum. Acta Obstet. Gynaecol. Scand. 80, 251-255.

13. O'Hara, M., Zekoski, E., Phillipps, L., and Wright, E. (1990) Controlled prospective study of postpartum mood disorders: comparison of childbearing and nonchildbearing women. J. Abnorm. Psychol. 99, 3-15.

14. Pitt, B. (1973) Maternity blues. Br. J. Psychiatry 122, 431-433.

15. Bergant, A., Heim, K., Ulmer, H., and Illmensee, K. (1999) Early postnatal depressive mood: associations with obstetric and psychosocial factors. J. Psychosom. Res. 46, 391-394.

16. Kumar, R. (1994) Postnatal mental illness: a transcultural perspective. Soc. Psychiatry Psychiatr. Epidemiol. 29, $250-$ 264.

17. Miller, L. and Rukstalis, M. (1999) Beyond the "blues": hypotheses about postpartum reactivity. In Postpartum Mood Disorders. Miller, L., Ed. American Psychiatrist Press, Washington, D.C. pp. 3-20.

18. Ingram, J., Greenwood, R., and Woolridge, M. (2003) Hormonal predictors of postnatal depression at 6 months in breastfeeding women. J. Reprod. Infant Psychol. 21, 61-68.

19. Nappi, R., Petraglia, F., Luisi, S., Polatti, F., Farina, C., and Genazzani, A. (2001) Serum allopregnanolone in women with postpartum "blues". Obstet. Gynecol. 97, 77-80.

20. Maayan, R., Fisch, B., Galdor, M., Kaplan, B., Shinnar, N., Kinor, N., Zeldich, E., Valevski, A., and Weizman, A. (2004) Influence of $17 \beta$-estradiol on the synthesis of reduced neurosteroids in the brain (in vivo) and in glioma cells (in vitro): possible relevance to mental disorders in women. Brain Res. 1020, 167-172.

21. Bailara, K., Henry, C., Lestage, J., Launay, J., Parrot, F., Swendsen, J., Sutter, A., Roux, D., Dallay, D., and DemotesMainard, J. (2006) Decreased brain tryptophan availability as a partial determinant of postpartum blues. Psychoneuroendocrinology 31, 407-413.

22. Kohl, C., Walch, T., Huber, R., Kemmler, G., Neurauter, G., Fuchs, D., Solder, E., Schrocksnadel, H., and SpernerUnterweger, B. (2005) Measurement of tryptophan, kynurenine and neopterin in women with and without postpartum blues. J. Affect. Disord. 86, 135-142.

23. Maes, M., Verkerk, R., Bonaccorso, S., Ombelet, W., Bosmans, E., and Scharpe, S. (2002) Depressive and anxiety symptoms in the early puerperium are related to increased degradation of tryptophan into kynurenine, a phenomenon which is related to immune activation. Life Sci. 71, 1837-1848.

24. Beck, C.T. (2001) Predictors of postpartum depression: an update. Nurs. Res. 50, 275-285.

25. Halbreich, U. (2005) Postpartum disorders: multiple interacting underlying mechanisms and risk factors. J. Affect. Disord. 88, 1-7.

26. American Psychiatric Association (2000) Diagnostic and Statistical Manual of Mental Disorders IV: Text Revised. American Psychiatric Association, Washington, D.C. 
27. Spinelli, M. (2001) A systematic investigation of 16 cases of neonaticide. Am. J. Psychiatry 158, 811-813.

28. Lindahl, V., Pearson, J., and Colpe, L. (2005) Prevalence of suicidality during pregnancy and the postpartum. Arch. Womens Ment. Health 8, 77-87.

29. Gavin, N., Gaynes, B., Lohr, K., Meltzer-Brody, S., Gartlehner, G., and Swinson, T. (2005) Perinatal depression: a systematic review of prevalence and incidence. Obstet. Gynecol. 106, 1071-1083.

30. Yonkers, K., Ramin, S., Rush, A.J., Navarrete, C., Carmody, T., March, D., Heartwell, S., and Leveno, K. (2001) Onset and persistence of postpartum depression in an inner-city maternal health clinic system. Am. J. Psychiatry 158, $1856-1863$.

31. Hobfoll, S., Ritter, C., Lavin, J., Hulsizer, M., and Cameron, R. (1995) Depression prevalence and incidence among inner-city pregnant and postpartum women. J. Consult. Clin. Psychol. 63, 445-453.

Baker, L., Cross, S., Greaver, L., Wei, G., Lewis, R., and Healthy Start CORPS (2005) Prevalence of postpartum depression in a Native American population. Matern. Child Health J. 9, 21-25.

33. Goyal, D., Murphy, S., and Cohen, J. (2006) Immigrant Asian Indian women and postpartum depression. J. Obstet. Gynecol. Neonatal Nurs. 35, 98-103.

34. Abbott, M. and Williams, M. (2006) Postnatal depressive symptoms among Pacific mothers in Auckland: prevalence and risk factors. Aust. N. Z. J. Psychiatry 40, 230-238. Onozawa, K., Kumar, R., Adams, D., Dore, C., and Glover, V. (2003) High EPDS scores in women from ethnic minorities living in London. Arch. Womens Ment. Health 6, s51-s55.

36. Munk-Olsen, T., Laursen, T., Pedersen, C., Mors, O., and Mortensen, P. (2006) New parents and mental disorders: a population based register study. JAMA 296, 2582-2618.

37. Bennett, S. and Indman, P. (2003) Beyond the Blues: A Guide to Understanding and Treating Prenatal and Postpartum Depression. Moodswings Press, San Jose, CA.

38. Ross, E. and McLean, L. (2006) Anxiety disorders during pregnancy and the postpartum period: a systematic review. J. Clin. Psychiatry 67(8), 1285-1298.

39. White, T., Matthey, S., Boyd, K., and Barnett, B. (2006) Postnatal depression and post traumatic stress after childbirth: prevalence, course and concurrence. J. Reprod. Infant Psychol. 24, 107-120.

40. Wenzel, A., Gorman, L., O'Hara, M., and Stuart, S. (2001) The occurrence of panic and obsessive compulsive symptoms in women with postpartum dysphoria: a prospective study. Arch. Womens Ment. Health 4, 5-12.

41. Robertson, E., Grace, S., Wallington, T., and Stewart, D. (2004) Antenatal risk factors for postpartum depression: a synthesis of recent literature. Gen. Hosp. Psychiatry 26, 289-295.

42. Dennis, C. and Ross, L. (2006) The clinical utility of maternal self-reported personal and familial psychiatric history in identifying women at risk for postpartum depression. Acta Obstet. Gynecol. 85, 1179-1185.

43. Forty, L., Jones, L., Macgregor, S., Caesar, S., Cooper, C., Hough, A., Dean, L., Dave, S., Farmer, A., McGuffin, P., Brewster, S., Craddock, N., and Jones, I. (2006) Familiality of postpartum depression in unipolar disorder: results of a family study. Am. J. Psychiatry 163, 1549-1553.

44. Murphy-Eberenz, K., Zandi, P., March, D., Crowe, R., Scheftner, W., Alexander, M., McInnis, M., Coryell, W., Adams, P., DePaulo, R., Miller, E., Marta, D., Potash, J., Payne, J., and Levinson, D. (2006) Is perinatal depression familial? J. Affect. Disord. 90, 49-55.

45. Bloch, M., Rotenberg, N., Koren, D., and Klein, E. (2005) Risk factors associated with the development of postpartum mood disorders. J. Affect. Disord. 88, 9-18.

46. Segre, L., O'Hara, M., Arndt, S., and Stuart, S. (2007) The prevalence of postpartum depression: the relative significance of three social status indices. Soc. Psychiatry Psychiatr. Epidemiol. 42, 316-312.

47. Mazzeo, S., Landt, M., Jones, I., Mitchell, K., Kendler, K., Neagle, M., Aggen, S., and Bulik, C. (2006) Associations among postpartum depression, eating disorders, and perfectionism in a population sample of adult women. Int. J. Eat. Disord. 39, 202-211.

48. Bloch, M., Schmidt, P., Danaceau, M., Murphy, J., Nieman, L., and Rubinow, D. (2000) Effects of gonadal steroids in women with a history of postpartum depression. Am. J. Psychiatry 157, 924-930.

49. Mian, A. (2005) Depression in pregnancy and the postpartum period: balancing adverse effects of untreated illness with treatment risks. J. Psychiatr. Pract. 11, 389-396.

50. Stowe, Z., Hostetter, A., and Newport, D. (2005) The onset of postpartum depression: implications for clinical screening in obstetrical and primary care. Am. J. Obstet. Gynecol. 192, 522-526.

51. Nordeng, H., Lindermann, R., Perminov, K., and Reikvam, A. (2001) Neonatal withdrawal syndrome after in utero exposure to serotonin reuptake inhibitors. Acta Psychiatr. Scand. 90, 288-291.

52. Bonari, L., Pinto, N., Ahn, E., Einarson, A., Steiner, M., and Koren, G. (2004) Perinatal risks of untreated depression during pregnancy. Can. J. Psychiatry 49, 726-735.

53. Flynn, H., Blow, F., and Marcus, S. (2006) Rates and predictors of depression treatment among pregnant women in hospital-affiliated obstetrics practices. Gen. Hosp. Psychiatry 28, 289-295.

54. Blier, P. (2006) Pregnancy, depression, antidepressants and breast-feeding. J. Psychiatry Neurosci. 31, $226-228$.

55. Chaudron, L., Kitzman, H., Peifer, K., Morrow, S., Perez, L., and Newman, M. (2005) Self recognition of and provider response to maternal depressive symptoms in low-income Hispanic women. J. Womens Health 14, 331-338. Scrandis, D. (2005) Normalizing postpartum depressive symptoms with social support. J. Psychiatr. Nurses Assoc. 11, 223-230. 
57. Morris-Rush, J., Freda, M., and Bernstein, P. (2003) Screening for postpartum depression in an inner-city population. Am. J. Obstet. Gynecol. 188, 1217-1219.

58.

59.

60.

61.

62.

63.

64.

65.

66.

67.

68.

69.

70.

71.

72.

73.

74.

75.

76.

77.

78.

79.

80.

81.

82.

83.

84.

85.

86.

87.

(2006). The postpartum depression law (N.J.S.A 26:2-176).

Cox, J., Holden, J., and Sagovsky, R. (1987) Detection of postnatal depression: development of the 10-item Edinburgh Postnatal Depression Scale. Br. J. Psychiatry 150, 782-786.

Beck, C.T. and Gable, R. (2002) The Postpartum Depression Screening Scale. Western Psychological Services, Los Angeles.

Beck, C.T. (2001) Further validation of the Postpartum Depression Screening Scale. Nurs. Res. 50, 155-164.

Harlow, B., Vitonis, A., Sparen, P., Cnattingius, S., Joffe, H., and Hultman, C. (2007) Incidence of hospitalization for postpartum psychotic and bipolar episodes in women with and without prior prepregnancy or prenatal psychiatric hospitalizations. Arch. Gen. Psychiatry 64, 42-48.

Jones, I. and Craddock, N. (2001) Familiality of the puerperal trigger in bipolar disorder: results of a family study. Am. J. Psychiatry 158, 913-917.

Robling, S., Paykel, E., Dunn, V., Abbott, R., and Katonah, C. (2000) Long-term outcome of severe puerperal psychiatric illness: a 23 year follow-up study. Psychol. Med. 30, 1263-1271.

Nager, A., Johnansson, L., and Sundquist, K. (2006) Neighborhood socioeconomic environment and risk of postpartum psychosis. Arch. Womens Ment. Health 9, 81-86.

Ahokas, A., Aito, M., and Rimon, R. (2000) Positive treatment effect of estradiol in postpartum psychosis: a pilot study. J. Clin. Psychiatry 61, 166-170.

Prendergast, J. and Austin, M. (2001) Early childhood nurse-delivered cognitive behavioral counselling for post-natal depression. Australas. Psychiatry 9, 255-259.

Clark, R., Tluczek, A., and Wenzel, A. (2003) Psychotherapy for postpartum depression: a preliminary report. Am. J. Orthopsychiatry 73, 441-454.

O'Hara, M. (2000) Efficacy of interpersonal psychotherapy for postpartum depression. Arch. Gen. Psychiatry 57,

1039-1045.

psychological treatment of postpartum depression. Br. J. Psychiatry 182, 412-419.

Klier, C., Muzik, M., Rosenblum, K., and Lenz, G. (2001) Interpersonal psychotherapy adapted for the group setting in the treatment of postpartum depression. J. Psychother. Pract. Res. 10, 124-131.

Pearlstein, T., Zlotnick, C., Battle, C., Stuart, S., O'Hara, M., Price, A., Grause, M., and Howard, M. (2006) Patient choice of treatment for postpartum depression: a pilot study. Arch. Womens Ment. Health 9, 303-308.

Boath, E., Bradley, E., and Henshaw, C. (2004) Women's views of antidepressants in the treatment of postnatal depression. J. Psychosom. Obstet. Gynecol. 25, 221-233.

4. Lee-Dennis, C. and Chung-Lee, L. (2006) Postpartum depression help-seeking barriers and maternal treatment preferences: a qualitative systematic review. Birth 33, 323-331.

Chabrol, H., Teissedre, F., Armitage, J., Danel, M., and Walburg, V. (2004) Acceptability of psychotherapy and antidepressants for postnatal depression among newly delivered mothers. J. Reprod. Infant Psychol. 22, 5-12.

Verkerk, G., Denollet, J., Van Heck, G., Van Son, M., and Pop, V. (2004) Patient preference for counselling predicts postpartum depression: a prospective 1 year follow up study in high risk women. J. Affect. Disord. 83, 43-48.

7. Hendrick, V., Altshuler, L., Strouse, T., and Grosser, S. (2000) Postpartum and nonpostpartum depression: differences in presentation and response to pharmacologic treatment. Depress. Anxiety 11, 66-72.

Sharma, V. (2006) A cautionary note on the use of antidepressants in postpartum depression. Bipolar Disord. 8, 411414.

Gjerdingen, D. (2003) The effectiveness of various postpartum depression treatments and the impact of antidepressant drugs on nursing infants. J. Am. Board Fam. Pract. 16, 372-382.

Wisner, K., Hanusa, B., Perel, J., Peindl, K., Piontek, C., Sit, D., Findling, R., and Moses-Kolko, E. (2006) Postpartum depression: a randomized trial of sertraline versus nortriptyline. J. Clin. Psychopharmacol. 26, 353-360.

Appley, L., Warner, R., Whitton, A., and Faragher, B. (1997) A controlled study of fluoxetine and cognitivebehavioural counselling in the treatment of postnatal depression. BMJ 314, 932.

Suri, R., Stowe, Z., Hendrick, V., Hostetter, A., Widawski, M., and Altshuler, L. (2002) Estimates of nursing infant daily does of fluoxetine through breast milk. Biol. Psychiatry 52, 446-451.

3. Suri, R., Vivien, K., Altshuler, L., Zuckerbrow-Miller, J., and Fairbanks, L. (2001) Fluvoxamine for postpartum depression. Am. J. Psychiatry 158, 1739-1740.

4. Nonacs, R.M., Soares, C., Viguera, A.C., Pearson, K., Poitras, J., and Cohen, L.S. (2005) Bupropion SR for the treatment of postpartum depression: a pilot study. Int. J. Neuropsychopharmacol. 8, 445-449.

Cohen, L.S., Viguera, A.C., Bouffard, S.M., Nonacs, R.M., Morabito, C., Collins, M.H., and Ablon, J.S. (2001) Venlafaxine in the treatment of postpartum depression. J. Clin. Psychiatry 62, 592-596.

DeVriese. (2003) Low serum n-3 polyunsaturated fatty acid (PUFA) predicts occurrence of postpartum depression. Life Sci. 73, 3181-3187.

7. Otto, S., deGroot, R., and Hornstra, G. (2003) Increased risk of postpartum depressive symptoms is associated with slower normalization after pregnancy of the functional docosahexaenoic acid status. Prostaglandins Leukot. Essential Fatty Acids 69, 237-243. 
88. Hibbeln, J. (2002) Seafood consumption, the DHA content of mothers' milk and prevalence rates of postpartum depression: a cross national, ecological analysis. J. Affect. Disord. 69, 15-29.

89. Levant, B., Ozias, M., and Carlson, S. (2007) Specific brain regions of female rats are differentially depleted of docosahexaenoic acid by reproductive activity and an fatty acid deficient diet. J. Nutr. 137, 130-134.

90. Freeman, M., Hibbeln, J., Wisner, K., Brumbach, B., Watchman, M., and Gelenberg, A. (2006) Randomized dose ranging pilot trial of omega-3 fatty acids for postpartum depression. Acta Psychiatr. Scand. 113, 31-35.

91. Marangell, L., Martinez, J., Zboyan, H., Chong, H., and Puryear, L. (2004) Omega-3 fatty acids for the prevention of postpartum depression: negative data from a preliminary open label pilot study. Depress. Anxiety 19, $20-23$.

92. Browne, J., Scott, K., and Silvers, K. (2006) Fish consumption in pregnancy and omega-3 status after birth are not associated with postnatal depression. J. Affect. Disord. 90, 131-139.

93. Llorente, A., Jensen, C., Voigt, R., Fraley, J., Berretta, M., and Heird, W. (2003) Effect of maternal docosahexaenoic acid supplementation on postpartum depression and information processing. Am. J. Obstet. Gynecol. 188, 1348-1353.

94. Linde, K., Mulrow, C., Berner, M., and Egger, M. (2005) St John's wort for depression. Cochrane Database Syst. Rev. (2), CD000448

95. Rayburn, W., Dix Christensen, H., and Gonzalez, C. (2000) Effect of antenatal exposure to St. John's wort (hypericum) on neurobehavior of developing mice. Am. J. Obstet. Gynecol. 183, 1225-1231.

96. Gregoretti, B., Stebel, M., Candussio, L., Crivellato, E., Bartoli, F., and Decorti, G. (2004) Toxicity of hypericum perforatum (St. John's Wort) administered during pregnancy and lactation in rats. Toxicol. Appl. Pharmacol. 200, 201-205.

97. Klier, C., Schmid-Seigel, B., Schafer, M., Lenz, G., Saria, A., Lee, A., and Zernig, G. (2006) St. John's wort (hypericum perforatum) and breastfeeding: plasma and breast milk concentrations of hyperforin for 5 mothers and 2 infants. J. Clin. Psychiatry 67, 305-309.

98. Lee, A., Minhas, R., Matsuda, N., Lam, M., and Ito, S. (2003) The safety of St. John's wort (hypericum perforatum) during breastfeeding. J. Clin. Psychiatry 64, 966-968.

99. Oren, D., Wisner, K., and Spinelli, M. (2002) An open trial of morning light therapy for treatment of antepartum depression. Am. J. Psychiatry 159, 666-669.

100. Corral, M., Kuan, A., and Kostaras, D. (2000) Bright light therapy's effect on postpartum depression. Am. J. Psychiatry 157, 303-304.

101. Epperson, C., Terman, M., Terman, J., Hanusa, B., Oren, D., Peindl, K., and Wisner, K. (2004) Randomized clinical trial of bright light therapy for antenatal depression. J. Clin. Psychiatry 65, 421-425.

102. Ahokas, A., Kaukoranta, J., Wahlbeck, K., and Aito, M. (2001) Estrogen deficiency in severe postpartum depression: successful treatment with sublingual physiologic 17(beta) estradiol: a preliminary study. J. Clin. Psychiatry 62, 332336.

103. Gregoire, A. and Kumar, R. (1996) Transdermal oestrogen for treatment of severe postnatal depression. Lancet 347, 930-934.

104. Dennis, C., Ross, L., and Herxheimer, A. (1999) Oestrogens and progestins for preventing and treating postpartum depression. Cochrane Database Syst. Rev. (3) CD001690

105. Lawrie, T., Hofmeyr, G.J., DeJager, M., Berk, M., Paiker, J., and Viljoen, E. (1998) A double-blind randomised placebo controlled trial of postnatal norethisterone enanthate: the effect on postnatal depression and serum hormones. Br. J. Obstet. Gynecol. 105, 1082-1090.

106. Weissman, A.M., Levy, B.T., Hartz, A.J., Bentler, S., Donohue, M., Ellingrod, V.L., and Wisner, K.L. (2004) Pooled analysis of antidepressant levels in lactating mothers, breast milk, and nursing infants. Am. J. Psychiatry 161, 10661078.

107. Spinelli, M. (2005) Letter to the editor: Dr. Spinelli replies. Am. J. Psychiatry 162, 1229.

108. Epperson, C. (1999) Postpartum major depression: detection and treatment. Am. Fam. Physician 59(8), 2247-2254, 2259-2260, accessed May 28, 2007 from http://www.aafp.org/afp/990415ap/2247.html.

109. Witt, K. and Franzblau, N. (2006) Normal and abnormal puerperium. eMedicine, accessed May 31, 2007 from http://www.emedicine.com/med/topic3240.htm.

110. Groer, M.W. and Morgan, K. (2007) Immune, health and endocrine characteristics of depressed postpartum mothers. Psychoneuroendocrinology 32, 133-139.

111. Maes, M., Lin, A., Ombelet, W., Stevens, K., Kenis, G., DeJongh, R., Cox, J., and Bosmans, E. (2000) Immune activation in the early puerperium is related to postpartum anxiety and depression symptoms. Psychoneuroendocrinology 25, 121-137.

\section{This article should be cited as follows:}

Scrandis, D.A., Sheikh, T.M., Niazi, R., Tonelli, L.H., and Postolache, T.T. (2007) Depression after delivery: risk factors, diagnostic and therapeutic considerations. TheScientificWorldJOURNAL: TSW Child Health \& Human Development 7, 16701682. DOI 10.1100/tsw.2007.207. 


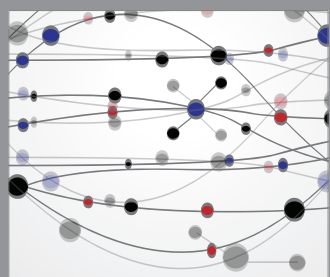

The Scientific World Journal
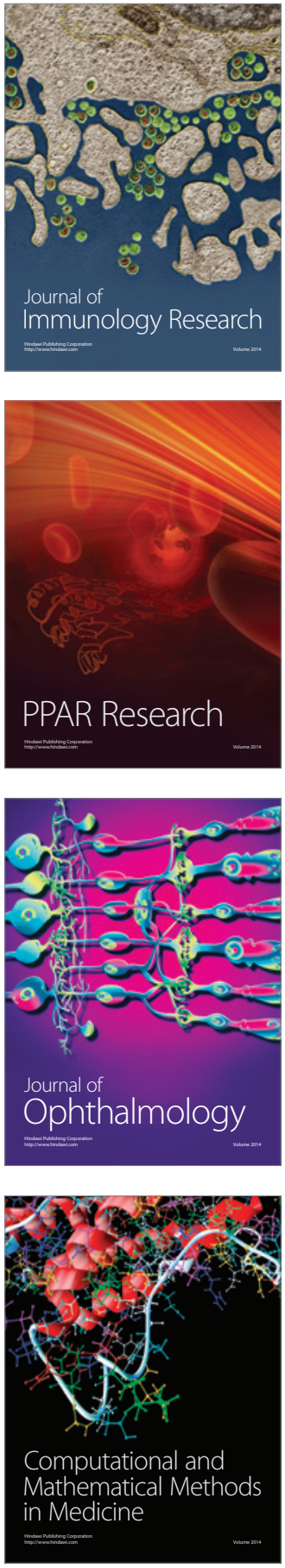

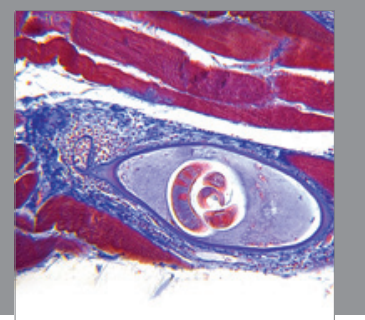

Gastroenterology

Research and Practice
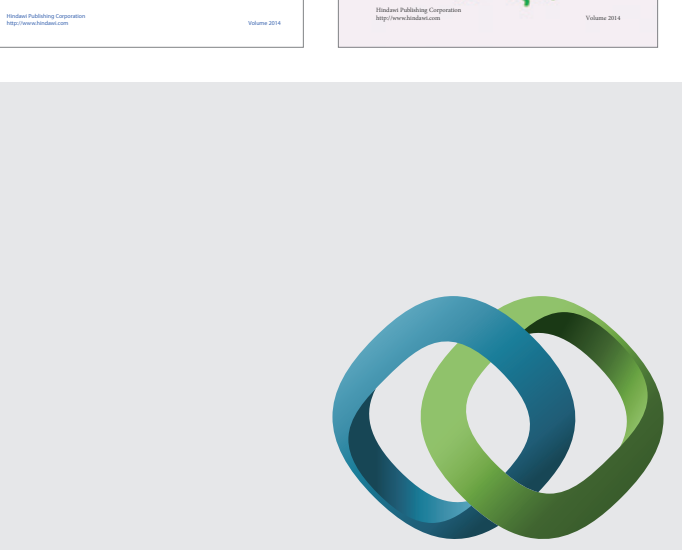

\section{Hindawi}

Submit your manuscripts at

http://www.hindawi.com
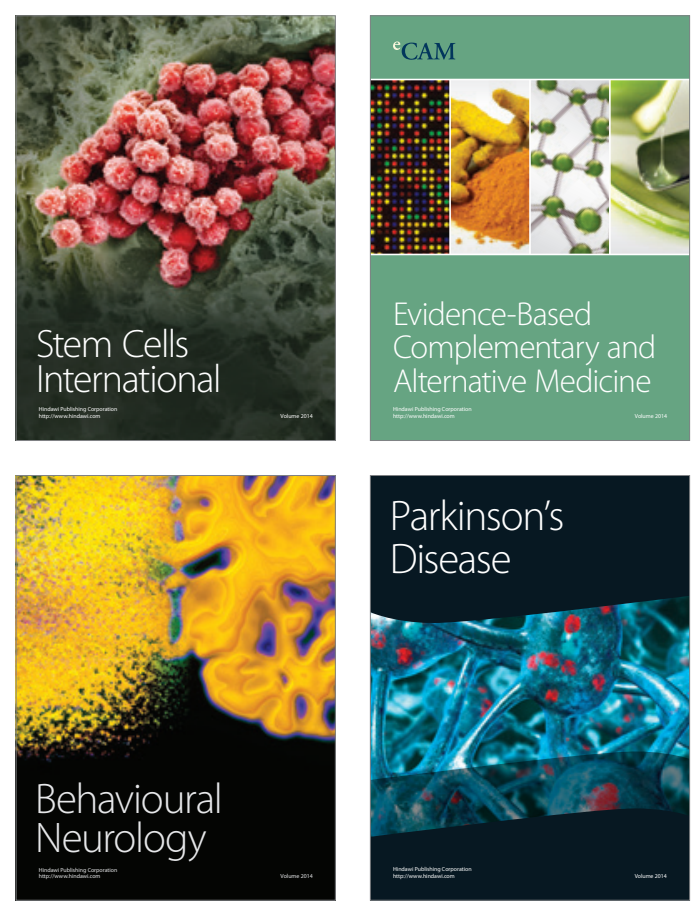

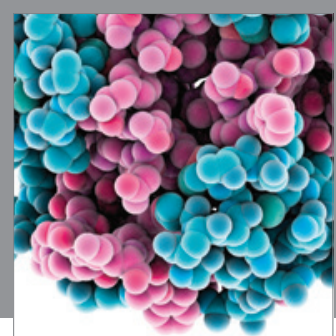

Journal of
Diabetes Research

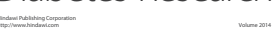

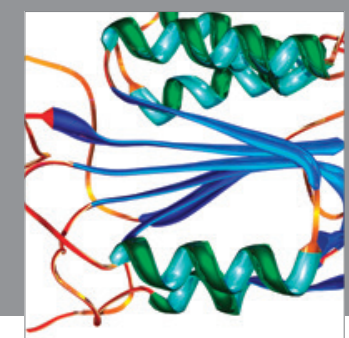

Disease Markers
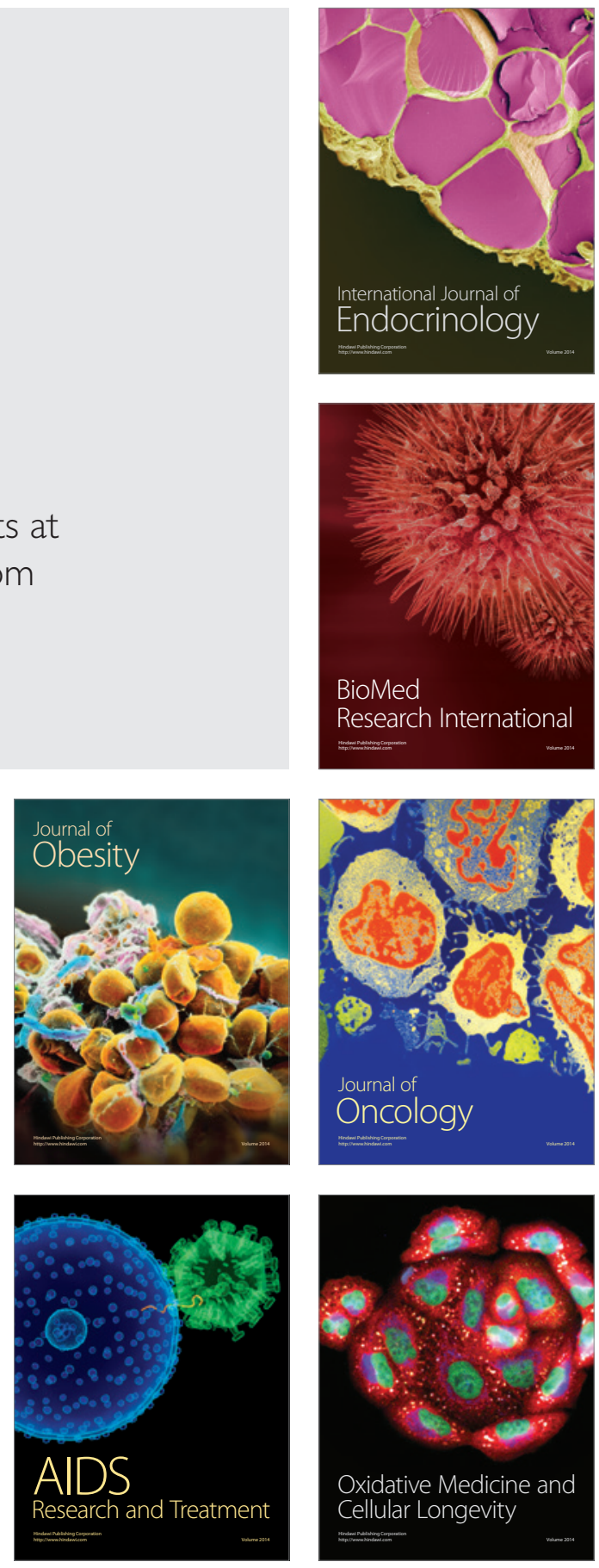